\title{
Strengthening the Human Development Indicators to Minimize the Health inequity and Health Disparities in United States of America: A case in Point of the African-American Community
}

\author{
Adetutu Alexandra Oseni \\ Southern University and A \& M College; Department of Public Policy \\ Baton Rouge, Louisiana \\ Adetutuo2002@yahoo.com
}

\begin{abstract}
This study examines the following Human Development Indicators such as education, income, poverty, employment and other growth factors and their respective relationship with health equity and equality. The study used 2017 US Census Bureau and 2017 US Department of Health datasets for the examination. The study examines the datasets related to the top ten (10) United States of America states dominated by African-American Population. The study revealed that health inequity leads to health disparities. Therefore, ensuring equal access to health insurance, education, resources, employment and many other human growth and development indicators are more likely to improve the lives of the citizens across the different racial groups in the nation. Because the finding is attributing the high disparities to health inequity in the ten (10) states, including unequal access to health care and other human development growth indicators such as income, employment and education. Therefore, the study recommends that federal government, policymakers, lawmakers, governors and mayors should collaborate with local, regional, state, and national partners from public health and social justice communities to advance health equity, and to help solidify a movement for progressive health equity practice; promote the work of other health departments to make the case for investing in health equity work; work with community organizers to train health department staff on the principles and practices of community organizing; hold provider networks and other public health system partners accountable for advancing health equity; and finally, listen and learn from broader social movements to better understand their issues, processes, and narratives, and how they can build power and motivate their base to ensure health equity.
\end{abstract}

Keyword: Health, Disparities, HDI, Employment, Income, Education, Insurance, Inequity, and Poverty

DOI: $10.7176 /$ JPID/54-06

Publication date:June $30^{\text {th }} 2020$

\section{INTRODUCTION}

As observed in the literature, health disparities are inevitable components of health inequity. Meanwhile, the subject of what distribution of resources, welfare or capabilities should be considered just (or equitable) has been highly controversial and debatable. In the interim, the early contributions to such debate has established the inherent equality of all people in terms of certain fundamental rights - they include John Locke in 1690 who argued that all human beings have a right to self-ownership and freedom, and Immanuel Kant in 1797 who also argued for universal human value, by virtue of being human. According to Burchardt (2006), the idea of the inherent equality of human rights continues to exert a powerful influence - in the UN Declaration of Human Rights, for example, which accords unconditional rights to all people, and in subsequent conventions referring, for example, to the rights of disabled people and those of women. In the meantime as with other welfare measures perceived by John Rawls, inequality has been conventionally considered in the area of resources as 'primary goods' and utility that practically serves as measures of income and consumption.

In the literature, it has also been observed that the capability approach is grounded in the notion of freedom. Sen (1987) argued that capabilities are notions of freedom in the positive sense, which investigate what real opportunities you have regarding the life you may lead (p. 36). Very importantly, the early scholars defined well-being as a function of resources and the ability to convert them into achievements, or functionings. This concept of capabilities has particular implications in the case of inequality. According to the literature, inequality refers to "differences, variation and disparities" in the characteristics of individuals and groups. Additionally, as 
perceived in the literature inequity and inequality are integral to the capability approach because of their links to distributive justice. Sen (1985) further argued that the case for a focus on reducing inequalities can be made on both intrinsic and instrumental grounds. He further argued that the arguments for the intrinsic value of greater equality take equity as a starting point, whereby equality of capabilities would be equitable. Surprisingly, it was observed in the literature that the distribution of capabilities typically cannot be observed, because it is concerned with substantive freedoms rather than outcomes (Sen, 1999). To a certain extent, the degree to which societies are inequitable must be inferred on the basis of inequalities in outcomes, and consideration of the process by which they come about. As argued in the Human Development Report (2011), inequalities in outcomes are largely the product of unequal access to capabilities (UNDP, 2011, p. 19). The report uses the Human Development Index (HDI) as a measure of growth and development across regions. According to the literature, the Human Development Index is a statistic composite index of life expectancy, education, and per capita income indicators, which are used to rank countries into four tiers of human development. Therefore, it is expected that a country will experience inequalities in outcomes (i.e. health disparities) there is an unequal access to capabilities such as education, employment, healthcare, and many others. Sometimes, all other things being equal people within a society may have equal capabilities, but we would not necessarily expect equal outcomes because people have different preferences and values. But we could be confident that those outcomes arose because of differences in people's choices rather than constraints on their abilities to exercise their choice. This implies to strengthen the Human Development Indicators such as education, income, life expectancy and gender equality then all constraints on the abilities to ones choice needs to be abolished.

According to Robeyns (2003), the degree to which predilections reflect choice can be difficult to determine because preferences and desires are often endogenous - a function of social construction rather than intrinsic difference. In addition, Burchardt (2006) also argued that the extent to which choice is exercised may be in some way linked to the complexity of the outcome considered, with more complex capabilities potentially involving more choice. In theory, we can therefore theorize that the health disparities among Americans could be attributed to choices and constraints on capabilities. As a result the arguments to mitigate inequalities in those areas can be generally agreed upon to be unjust - and, deductively forms the concept of injustice in distribution. In fact, the idea of injustice in distribution has been observed in standard of living, health and basic educationthereafter expanding to so-called higher-level capabilities. Many philosophers over the centuries have tried to establish what a just society would look like-often this hinges upon how much inequality is acceptable. In The Idea of Injustice, Sen (2011) argues for a pragmatic approach to reducing inequalities, where there is consensus that they are unjust, and to fighting such injustice even in the absence of full agreement as to the ideal society. This approach paves the way to collective deliberation and a focus on the most destructive inequalities. The policymakers' collection reflections aim at eliminating health inequity and disparities among different segments of the population in the United States of America. Health disparities are a major concern among Public Health Officials and governors.

According to health literature, Health disparities is defined as the differences in health that occur by gender, race or ethnicity, education or income, disability, living in rural localities, or sexual orientation (US Department of Health and Human Services Office of Disease Prevention and Health Promotion, 2010). In addition, the National Institutes of Health defined health disparities as "differences in the incidence, prevalence, mortality, and burden of diseases and other adverse health conditions that exist among specific population groups in the United States. Despite the numerous theories, health data, and concepts available to researchers and policymakers in United States and the current COVID-19 pandemic that has raised the current alarm on health disparities and inequity, whereby the rate of infections and mortality are high among the African-American community as compared to the racial groups, no single study has been designed to investigate into the matter. Therefore, this current study is devoted to examine the situation by using the available information or data to better inform policymakers and to also validate that the process of strengthening the Human Development Indicators or index will go a long way to minimize the health inequity and health disparities currently observed in the United States of America. This in effect will help improve that health status of the minority population (i.e. African-American Population). 


\section{LITERATURE REVIEW}

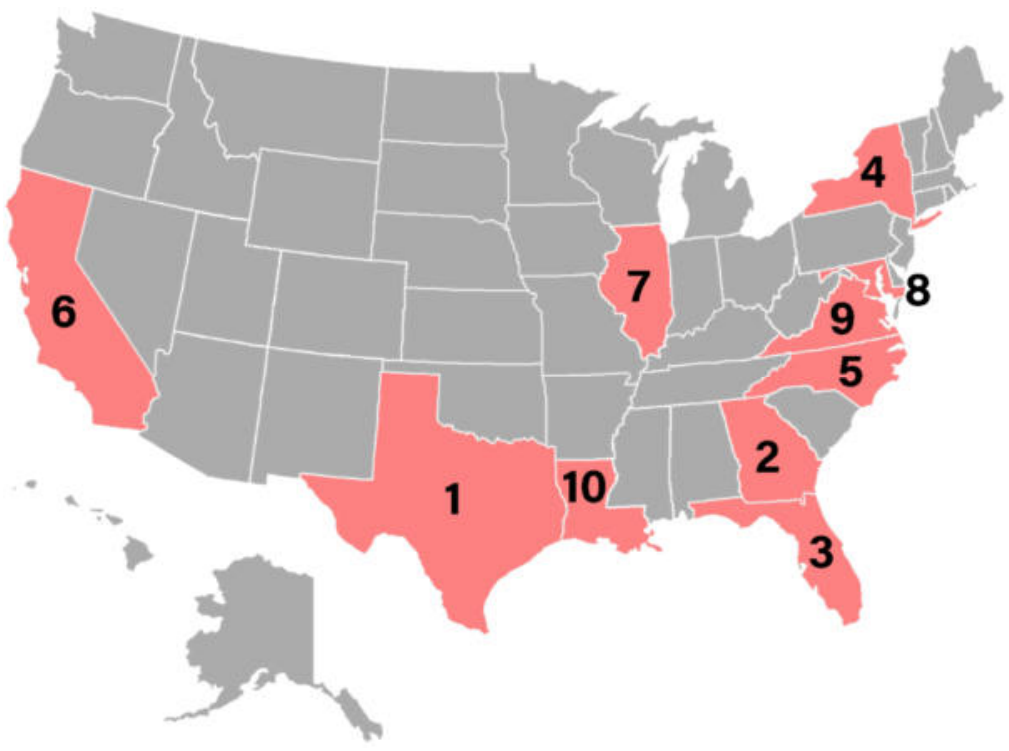

Figure 1: A Map of the US with the top 10 states displaying the largest African American population according to the Census Bureau.

Source: US Department of Health and Human Services (Office of Minority Health)

Figure 1 discusses a Map of the US with the top 10 states displaying the largest African American population according to the U.S. Census Bureau (2020). The number 1 in the map represent the state of Texas, 2 represent Georgia state, 3 represents Florida, 4 represents New York state, 5 represents North Carolina, 6 represents California, 7 represents Illinois state, 8 represents Maryland, 9 represents Virginia, and 10 represents Louisiana state. Surprisingly, in the midst of the COVID-19, this pandemic has revealed the extent of health inequality and inequity among the different racial/ethnic groups within the ten (10) states. Unfortunately, these states recorded the highest infection rate and mortality rate a typical case in points was observed in New York. Meanwhile, in the literature, it has been observed that health inequity or inequality widens the gap of health disparities. Therefore, it is theorized in this study that strengthening the HDI indicators such as ensuring justice in distribution of access to education, equitable distribution of resources, income, equal opportunity to employment, and equal access to health care (i.e. insurance) then the entire population will likely to measure as a healthy population to minimize health disparities. The above postulation has been examined in the following concepts: health, education, income, growth and poverty.

\section{Health}

According to World Health Organization, health is a state of physical, mental and social well-being in which disease and infirmity are absent (2006). In fact, the meaning of health has evolved over time. In keeping with the biomedical perspective, early definitions of health focused on the theme of the body's ability to function; health was seen as a state of normal function that could be disrupted from time to time by disease. An example of such a definition of health is: "a state characterized by anatomic, physiologic, and psychological integrity; ability to perform personally valued family, work, and community roles; ability to deal with physical, biological, psychological, and social stress" (Stokes, Noren, \& Shindell, 1982). Then in 1948, in a radical departure from previous definitions, the World Health Organization (WHO) proposed a definition that aimed higher: linking health to well-being, in terms of "physical, mental, and social well-being, and not merely the absence of disease and infirmity" (World Health Organization, 1958). Links between inequality and health focus on three main pathways: first, that high inequality is associated with more poverty, all else being equal, and possibly segregation - both of which have a pernicious effect on health; second, that it may erode social cohesion; and third, that it may negatively affect health related policies (Subramanian and Kawachi 2004, Kondo et al. 2009). Studies that seek to disentangle the effects of individual income and societal inequality give some support to the view that income inequality is associated with poorer health outcomes at the state and country levels, though not necessarily 
at local geographic levels. This could indicate the importance of political mechanisms in shaping social spending and of social stratification. A study by Marmot (2005) establishes direct linkages between socio-economic status and ill health-by arguing that a low social standing is linked with a higher incidence of depression (), and inequality with more mental illness. Wilkinson and Pickett (2010) also argued that people from lower socioeconomic backgrounds are less likely to be able to obtain treatment for medical conditions. For instance, in the case of depression, the World Mental Health Survey suggested treatment rates of between 1.6 percent (Nigeria) and 17.9 percent (United States) (Wilkinson and Pickett, 2010). In the literature, it has been underscored that the differences in gender, marriage, education and in the extremes of age or income were important factors to explain the differential levels of treatment (Wilkinson and Pickett, 2010; Blas and Kurup, 2010). As further observed in the literature, in rich countries in general, adult obesity, diabetes-related deaths and higher rates of teenage pregnancy correlate to income inequality (Wilkinson and Pickett, 2010; Blas and Kurup, 2010). Therefore, the percentage of overweight children is associated with inequality internationally (Wilkinson and Pickett, 2010; Blas and Kurup, 2010).

\section{Education}

Several studies point to the negative effect of income inequality upon educational attainment (Mayer, 2000; Haveman and Smeeding, 2006), which also carries implications for its intergenerational transmission. Inequality is inversely related to scores on reading and math scores both internationally (among developed countries) and within the 50 US states, as well as to high school dropout rates in US states (Wilkinson and Pickett, 2010). Mayer (2001) argued that the effect of inequality appears to be transmitted not through family income or economic segregation, but rather through levels of state spending on schooling. Such inequality often has a group dimension too that tends to cumulate over time, as has been shown in the case of ethnic minorities in the United States (Perreira et al., 2006). In turn, attitudes related to group identity may affect school enrolment and performance; one recent study of rural Pakistan found that caste stigma significantly dampens school enrolment among lowcaste children, particularly girls (Jacoby and Mansuri, 2011). According to Hoff and Pandey (2006), in India, experiments showed that low-caste children performed poorly on cognitive tests only when their caste status was made public. They further argued that inequalities in education are in some sense fundamental, with spillover impacts on employment prospects and wages, demographic effects (i.e. fertility rates), growth, poverty, intrahousehold bargaining power and governance. They underscored in the literature that there are examples of countries at all levels of development that have enacted growth policies favoring disadvantaged groups. Above all, a study by Grant (2005) examines the experiences of 14 countries in which growth increased, and inequality and poverty fell over the 1990s - namely Bangladesh, Bolivia, Brazil, Burkina Faso, El Salvador, Ghana, India, Indonesia, Romania, Senegal, Uganda, Viet Nam and Zambia.

\section{Income, Growth and Poverty}

Inequality tends to be significantly negatively associated with per capita income levels: not only are the poorest countries the most unequal, but also "no country has successfully developed beyond middle-income status while retaining a very high level of inequality in income or consumption" (Ferreira and Ravallion, 2008, p. 6). The relationship between inequality and growth is more complex. Cross-country econometric studies of the relationship between inequality and growth are mixed and largely inconclusive (Hillebrand, 2009, p. 7). It is clear, however, that inequality increases poverty for any level of growth, all else being equal. Globally, between 1981 and 2005 , while the impact of economic growth was to lift hundreds of millions of people out of poverty, increases in inequality meant than nearly 600 million people who otherwise would have escaped poverty were denied that chance (Hillebrand, 2009, p. 7).

\section{METHODOLOGY AND DISCUSSION}

The study utilized the Human Development Indicators such as education, life expectancy, income, poverty and health status in general to examine the ten (10) top states dominated by African-American population. The study retrieved data from the 2017 US Department of Health and Human Services (Office of Minority Health) and 2017 U. S Census Bureau datasets. The study is purely descriptive in nature. The study uses bar-graphs and pie-chart for the data presentation and discussion. In July 2017, 41.4 million people in the United States were black representing 12.7 percent of the total population (US Census Bureau, 2017). African Americans are the second largest minority population, following the Hispanic/Latino population. In 2017, most blacks lived in the South (58 percent of the black U.S. population), while 27 percent of the white population lived in the South. According to US Department of Health and Human Services (2020), the ten states with the largest black population in ranking 
as at 2017 were Texas, Georgia, Florida, New York, North Carolina, California, Illinois, Maryland, Virginia, Louisiana. Combined, these 10 states represent $58 \%$ of the total black population.

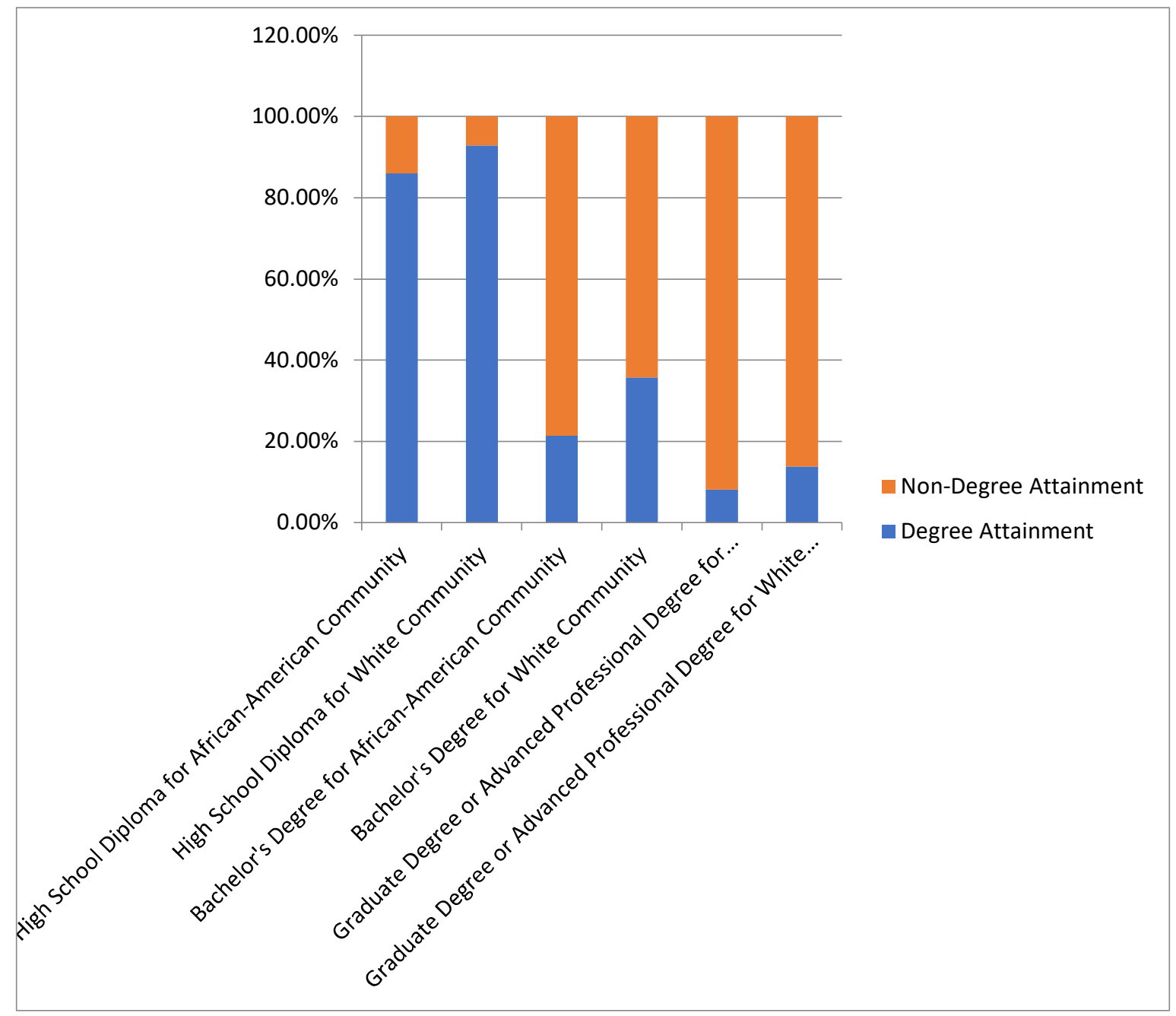

Figure 2: Disparities in Educational Attainment among Americans

Source: US Department of Health and Human Services (Office of Minority Health)

Figure 2 discusses the educational attainment among Americans. The analysis of Figure 2 further illustrates the racial distribution of educational attainment among Americans as at 2017. In 2017, as compared to non-Hispanic whites (or Whites) 25 years and over, 86.0 percent of non-Hispanic blacks (or African-Americans) had earned at least a high school diploma, as compared to 92.9 percent of the non-Hispanic white population (see Figure 2 for more details). In relation to Figure 2, about 21.4 percent of non-Hispanic blacks had a bachelor's degree or higher, as compared with 35.8 percent of non-Hispanic whites. More black women than black men had earned at least a bachelor's degree (23.8 percent compared with 18.5 percent), while among non-Hispanic whites, a higher proportion of women than men had earned at least a bachelor's degree (35.9 percent and 35.6 percent, respectively). Meanwhile, about 8.1 percent of non-Hispanic blacks have a graduate or advanced professional degree, as compared to 13.8 percent of the non-Hispanic white population. 


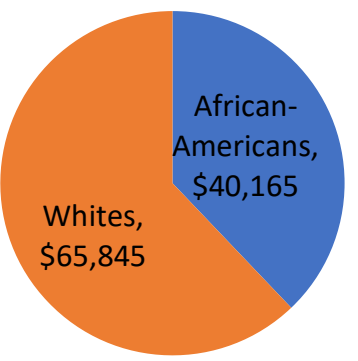

Figure 3: Average Household Median Income Distribution in United States of America

Source: U.S. Census Bureau, 2017

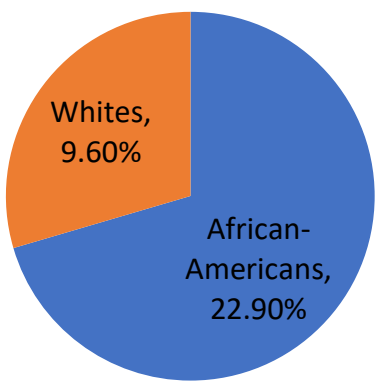

Figure 4: Percentage of Americans Living under Poverty Level

Source: U.S. Census Bureau, 2017

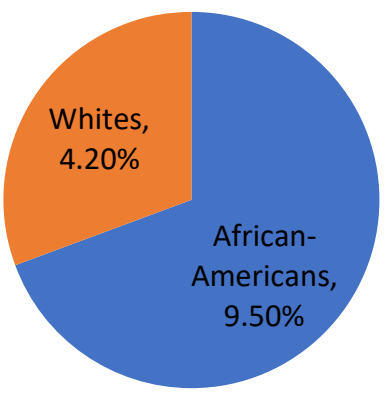

Figure 5: Disparities in Unemployment Rate in United States of America

Source: U.S. Census Bureau, 2017

Figures 3, 4 and 5 discuss the economic disparities data among Americans. In specific reference to the U.S. Census Bureau 2017 data, the average non-Hispanic black (African-American) median household income 
was $\$ 40,165$ in comparison to $\$ 65,845$ for non-Hispanic white (Whites) households (see Figure 3 for more details). In Figure 4, as revealed by the U.S. Census Bureau 2017 data, about 22.9 percent of non-Hispanic blacks (AfricanAmerican) in comparison to 9.6 percent of non-Hispanic whites (Whites) were living at the poverty level. As revealed in Figure 5, in 2017, the unemployment rate for blacks was twice that of non-Hispanic whites (9.5 percent and 4.2 percent, respectively).

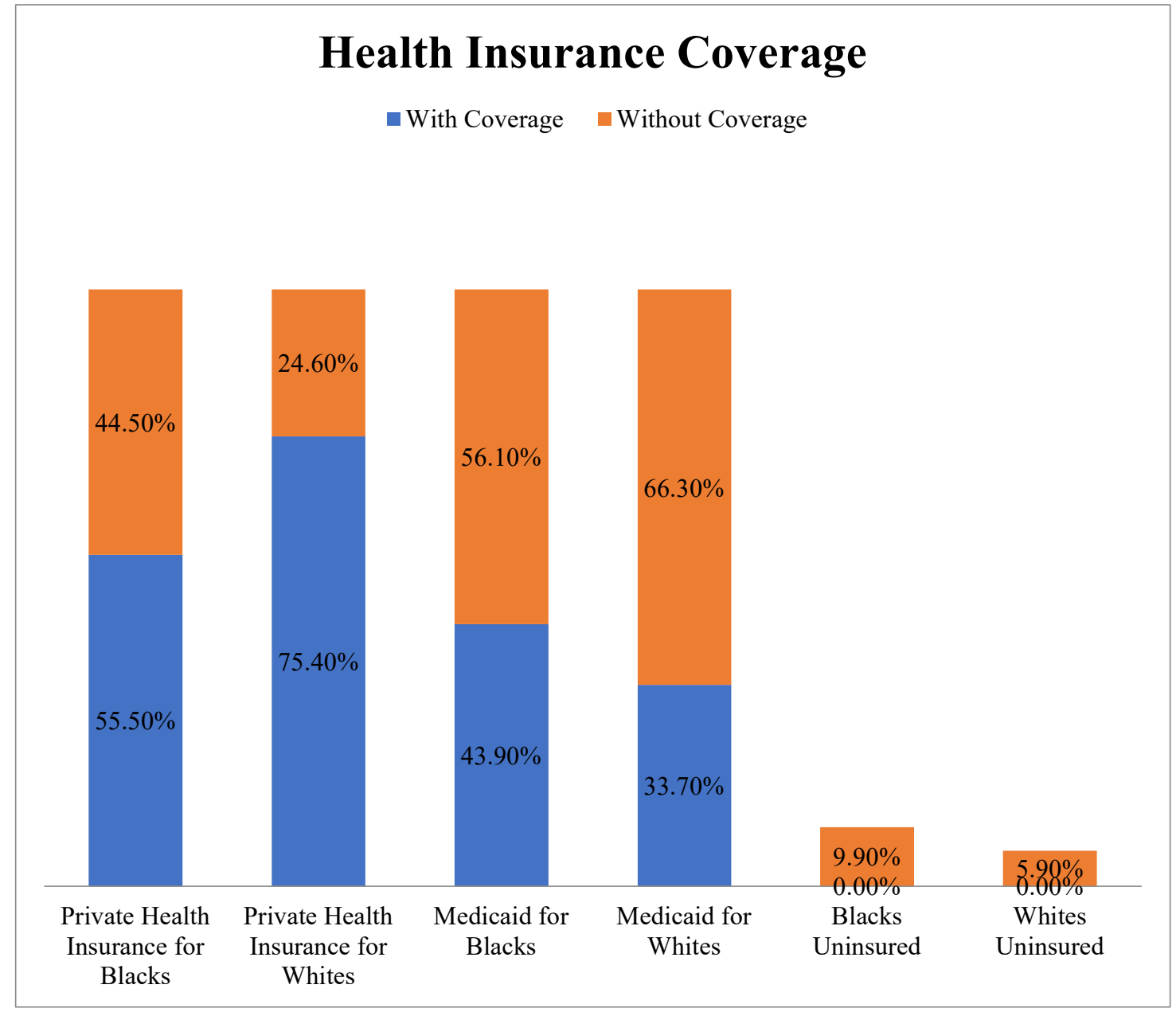

Figure 6: Disparities in Insurance Coverage among Americans

Source: US Department of Health and Human Services (Office of Minority Health)

Figure 6 discusses the insurance coverage among Americans. Figure 6 reveals that about 55.5 percent of non-Hispanic blacks in comparison to 75.4 percent of non-Hispanic whites used private health insurance based on the 2017 US Department of Health and Human Services (Office of Minority Health) health insurance coverage data. The data further revealed that about 43.9 percent of non-Hispanic blacks in comparison to 33.7 percent of non-Hispanic whites relied on Medicaid or public health insurance. Finally, about 9.9 percent of non-Hispanic blacks in comparison to 5.9 percent of non-Hispanic whites were uninsured (see Figure 6 for more details). 


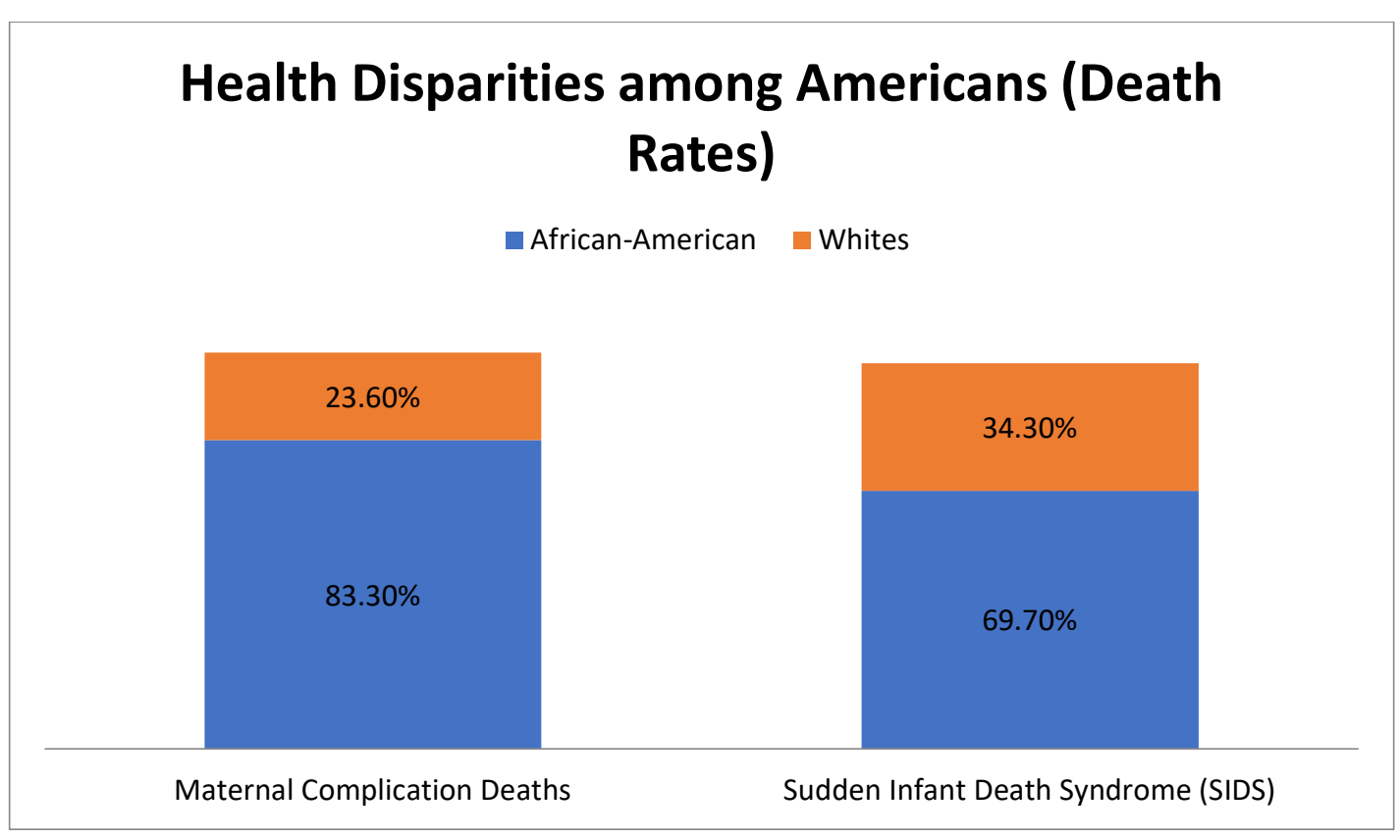

Figure 7: Health Disparities among Americans (Death Rates)

Source: US Department of Health and Human Services (Office of Minority Health)

Figure 7 discusses the health disparities among Americans (or differences in death rates). Based on the 2017 data, Figure 7 reveals that about $83.3 \%$ of African-Americans died as a result of maternal complications while $23.60 \%$ Whites died as a result of maternal complications. In addition, about $69.70 \%$ of African-Americans died as a result of sudden infant death syndrome (SIDS) while 34.30\% Whites died as a result of sudden infant death syndrome (SIDS). The data reveals that the death rate for African Americans is generally higher than whites for heart diseases, stroke, cancer, asthma, influenza and pneumonia, diabetes, HIV/AIDS, and homicide. All these diseases could be related to unequal access to health insurance, education, employment and resources. These findings are consistent with the findings that in rich countries in general, adult obesity, diabetes-related deaths and higher rates of teenage pregnancy correlate to income inequality. The percentage of overweight children is associated with inequality internationally. Even though there disparities in health and death rates among Americans, but in 2015 the U S Census Bureau projected that the life expectancies at birth for blacks will be at 76.1 years, with 78.9 years for women, and 72.9 years for men. For non-Hispanic whites the projected life expectancies is expected to be at 79.8 years, with 82.0 years for women, and 77.5 years for men. African American women have the highest rates of obesity or being overweight compared to other groups in the United States. About 4 out of 5 African American women are overweight or obese (US Department of Health and Human Services Office of Disease Prevention and Health Promotion, 2019). Additionally, in 2018, non-Hispanic blacks were 1.3 times more likely to be obese as compared to non-Hispanic whites. In 2018, African American women were 50 percent more likely to be obese than non-Hispanic white women (US Department of Health and Human Services Office of Disease Prevention and Health Promotion, 2019). From 2013-2016, non-Hispanic black females were 2.3 times more likely to be overweight as compared to non-Hispanic white females (US Department of Health and Human Services Office of Disease Prevention and Health Promotion, 2019). Above all, people who are overweight are more likely to suffer from high blood pressure, high levels of blood fats, diabetes and LDL cholesterol - all risk factors for heart disease and stroke (US Department of Health and Human Services Office of Disease Prevention and Health Promotion, 2019). All these underlying conditions make the minority more susceptible to the COVID-19 pandemic. As rightfully observed by Oseni (2020), in order for the federal government and policymakers to minimize the morbidity and mortality rates among the less privilege racial group due to health inequity, the author suggested that all COVID-19 preventive cares, possible treatment tools (or medication), screening and if possible vaccination must be either free or demanded at a subsidized rate in order make eradication possible to benefit the AfricanAmerican community. 


\section{CONCLUSION}

It is an undeniable fact; health inequity leads to health disparities. Therefore, ensuring equal access to health insurance, education, resources, employment and many other human growth and development indicators are more likely to improve the lives of the citizens across the different racial groups. Due to the high incidence of health inequity there has been growing evidence that more African Americans may be dying from COVID-19 in the United States than whites or other ethnic groups due to health inequity and high health disparities. As observed in the literature, the Black Americans representing 13.4\% of the American population, according to the US Census Bureau, and the counties with higher black populations accounted for more than half of all Covid-19 cases and almost $60 \%$ of deaths. This finding is attributed to high disparities, including unequal access to health care and other human development growth indicators such as income, employment and education. Therefore, this particular study recommends that policymakers, governors and mayors should collaborate with local, regional, state, and national partners from public health and social justice communities to advance equity (in education, insurance, income, health, e.t.c.), and to help solidify a movement for progressive health equity practice; promote the work of other health departments to make the case for investing in health equity work; work with community organizers to train health department staff on the principles and practices of community organizing; work with community organizers to include a message of health equity in their organizing efforts; support by increasing the voice and influence of communities impacted by health inequities in policy change; hold provider networks and other public health system partners accountable for advancing health equity; and finally, listen and learn from broader social movements to better understand their issues, processes, and narratives, and how they build power and motivate their base. By so doing will strengthen all the Human Development Indicators such as education, life expectancy, income per capita, growth, employment, and reduction in poverty.

\section{REFERENCES}

Blas, E., and Kurup, A. S. (2010). Equity, social determinants and public health programmes. World Health Organization, Geneva.

Braunstein, E., and Heintz, J. (2006). "Gender Bias and Central Bank Policy: Employment and Inflation Reduction." Working paper, project on Alternatives to Inflation Targeting. The Political Economy Research Institute, University of Massachusetts.

Burchardt, T. (2006). "Foundations for measuring equality: A discussion paper for the Equalities Review Panel." CSAE paper 111. Centre for the Analysis of Social Exclusion, London School of Econmics. http://eprints.lse. ac.uk/6236/.

Ferreira, F. H. G, and Gignoux, J. (2011). "The Measurement of Inequality of Opportunity: Theory And an Application to Latin America." Review of Income and Wealth 57(4): 622-657. International Association for Research in Income and Wealth.

Ferreira, F.H.G., and Ravallion, M. (2008). Global Poverty and Inequality: A review of the evidence. World Bank Policy Research Working Paper, number 4623. The World Bank, Washington, DC. http://go.worldbank.org/6IH5WG8QF0.

Graham, C., and Felton, A. (2006). "Inequality and happiness: Insights from Latin America." Journal of Economic Inequality 4(1): 107-122.

Grant, U. (2005). Pro-poor growth and the poorest. Background paper for the Chronic Poverty Report 2008-09. Chronic Poverty Research Centre, University of Manchester.

Hillebrand, E. (2009). Poverty, Growth and Inequality Over the Next 50 Years. Paper presented at Food and Agricultural Organization expert meeting on how to feed the world in 2050. 24-26 June, p. 7.

Hildebrand, V., and Van Kerm, P. (2009). Income inequality and self-rated health status: evidence from the European Community Household Panel. Demography 46(4): 805-825.

Hoff, K., and Pandey, P. (2006). Discrimination, social identify, and durable inequalities. American Economic Review (Papers \& Proceedings), 96(2): 206-211.

Jacoby, H. G., and Mansuri, G. (2011). Crossing boundaries: gender, caste and schooling in rural Pakistan. Policy Research Working Paper Series 5710. The World Bank, Washington, $D C$. www.econ.yale.edu/conference/neudc11/papers/paper_237.pdf.

Kondo, N., G.; Sembajwe, I.; Kawachi, R.; van Dam, S. S.; and Yamagata, Z. (2009). Income Inequality, Mortality and Self-rated Health: Meta-analysis of Multilevel Studies. British Medical Journal, 339: 447.

Marmot, M. (2005). Public Health Social Determinants of Health Inequalities. Lancet, 365: 1,099-1,104.

Mayer, S. E. (2000). Income Inequality, Economic Segregation and Children's 
Educational Attainment. JCPR Working Papers 209. Northwestern University/University of Chicago Joint Center for Poverty Research.

Oseni, A. A. (2020). Examining Implementation of Policy Effects on Coronavirus (Covid-19) in United State of America. Journal of Law, Policy and Globalization, Vol. 96, 2020.

Perreira, K. M.; Harris, K. M.; and Lee, D. (2006). Making it in America: High school completion by immigrant and native youth. Demography, 43: 511-536.

Robeyns, I. (2003). Sen's capability approach and gender inequality: selecting relevant capabilities. Feminist Economics, 9(2-3): 61-92.

Sen, A. K. (1973). On Economic Equality. Oxford University Press.

Subramanian, S.V., and Kawachi, I. (2004). Income Inequality and Health: What Have We Learned So Far? Epidemiologic Reviews, 26: 78-91.

Wilkinson, R., and Pickett. K. (2006). Income Inequality and Population Health: A Review and Explanation of the Evidence. Social Science \& Medicine, 62: 1,768-1,784. 